\title{
Coinfection with EBV/CMV and other respiratory agents in children with suspected infectious mononucleosis
}

\author{
Xia Wang ${ }^{1,2}$, Kun Yang ${ }^{1}$, Cong Wei ${ }^{1}$, Yuan Huang ${ }^{1}$, Dongchi Zhao ${ }^{1 *}$
}

\begin{abstract}
Background: Numerous studies have shown that Epstein-Barr virus (EBV) and cytomegalovirus (CMV) can infect immunocompetent patients simultaneously with other agents. Nonetheless, multiple infections with other agents in EBV/CMV-infected children have received little attention. We conducted a retrospective study of children with suspected infectious mononucleosis. Peripheral blood samples were analyzed by indirect immunofluorescence to detect EBV, CMV and other respiratory agents including respiratory syncytial virus; adenovirus; influenza virus types A and B; parainfluenza virus types 1,2 and 3; Chlamydia pneumoniae and Mycoplasma pneumoniae. A medical history was collected for each child.

Results: The occurrence of multipathogen infections was $68.9 \%, 81.3 \%$ and $63.6 \%$ in the children with primary EBV, CMV or EBV/CMV, respectively, which was significantly higher than that in the past-infected group or the uninfected group $(p<0.001)$. Of the multipathogen-infected patients, the incidence of $C$. pneumoniae in children with primary infection was as high as $50 \%$, significantly higher than in the other groups $(p<0.001)$. In the patients with multipathogen infection and EBV/CMV primary infection, fever, rash, lymphadenopathy, hepatomegaly, splenomegaly, atypical lymphocytes and abnormal liver function were more frequent and the length of hospital stay and duration of fever were longer than in other patients.

Conclusion: Our study suggests that there is a high incidence of multipathogen infections in children admitted with EBV/CMV primary infection and that the distribution of these pathogens is not random.
\end{abstract}

\section{Introduction}

Epstein-Barr virus (EBV) and Cytomegalovirus (CMV), members of the herpesvirus family, are common viruses that cause infectious mononucleosis (IM) characterized by fever, pharyngitis and lymphadenopathy. EBV/CMV infects at least $90 \%$ of the world's population and can persist in a latent form after primary infection. Reactivation can occur years later, particularly under conditions of immunosuppression [1,2]. The primary infection may occur shortly after the disappearance of maternal antibodies during infancy [3]. In childhood, EBV is the most common cause of IM, but primary CMV infection will cause up to $7 \%$ of cases of mononucleosis syndrome

\footnotetext{
* Correspondence: zhaodong@public.wh.hb.cn

'Pediatrics Department, Zhongnan Hospital, Wuhan University, Wuhan 430071, China

Full list of author information is available at the end of the article
}

and will manifest symptoms almost indistinguishable from those of EBV-induced mononucleosis [4].

It is well known that EBV and CMV are common opportunistic infection agents in the immunocompromised, including human immunodeficiency virus-infected individuals, and are a major source of serious viral complications in organ transplant recipients [5]. Children are also a susceptible population at high risk of CMV/EBV infection. During growth and development, CMV/EBV infection can depress the host immune response: this is a major cause of recurrent childhood microbial infection [6]. Because CMV and EBV have so much in common, coinfection with these two viruses occurs occasionally in children [7-9]. Numerous studies have shown that EBV/ CMV can infect immunocompetent patients simultaneously with other agents including respiratory syncytial virus (RSV), Chlamydia pneumoniae (CP), human herpesvirus 6 , measles virus and others[7,10-14], and it has
C Biomed Central

C 2010 Wang et al; licensee BioMed Central Ltd. This is an Open Access article distributed under the terms of the Creative Commons Attribution License (http://creativecommons.org/licenses/by/2.0), which permits unrestricted use, distribution, and reproduction in any medium, provided the original work is properly cited. 
been reported that EBV/CMV-infected children with no detected immune deficiency can suffer from mixed infections with other agents[12,14]. In a previous study, we found that multipathogen infection is not random but is related to specific agents. Nonetheless, multiple infections of EBV/CMV and other agents have received little attention. The aim of this study was to explore the clinical features and incidence of coinfection of EBV/CMV and respiratory pathogens in children hospitalized with suspected IM.

\section{Results}

\section{Clinical features}

\section{EBV infection}

Of the 190 patients, 164 had detectable EBV antibodies. The age range of this group was from 1-164 months (mean $46.9 \pm 35.7$ months) with a male: female ratio of 1.73:1 (102 boys and 62 girls). Forty patients had primary EBV infection, 48 past infection and 76 were uninfected. The clinical characteristics of these three groups are presented in Table 1 . There were no differences between the groups in incidence of fever, rash, palatal petechiae or splenomegaly, but the mean hospital stay in the past-infected group was the shortest $(7.71 \pm$ 3.07 days). The patients with EBV primary infection had a higher incidence of lymphadenopathy than the other two groups $(p<0.001)$. In the primary-infection and past-infected groups pharyngitis and hepatomegaly were more frequent than in uninfected patients $(p=0.02$ and 0.013 , respectively). There were no differences between these three groups in their main laboratory results, except that the percentage of patients with $>10 \%$ atypical lymphocytes was higher in the primary- and pastinfected groups than in the uninfected group and the frequency of C-reactive protein (CRP) $>10 \mathrm{mg} / \mathrm{L}$ was significantly lower in the primary-infection group.

\section{CMV infection}

Of the 190 patients, 165 had the test for CMV-specific antibodies, including 106 boys and 59 girls (a male:female ratio of 1.80:1) with ages ranging from 1-164 months (mean $43.5 \pm 35.4$ months). Twenty-five patients had primary CMV infection, 104 were past-infected and 36 uninfected. Compared with the other two groups, the primary-infection group had a longer hospital stay and more frequent presentation of palatal petechiae, hepatomegaly and splenomegaly, atypical lymphocytes $>10 \%$ and abnormal liver function, but fewer rashes. Although the total numbers of white blood cells (WBC), platelet and hemoglobin values did not differ among groups, the primary-infected children had the lowest percentage of neutrophils $(24.15 \pm 15.70 \%, p=0.001)$ and the highest percentage of lymphocytes $(62.03 \pm 16.74 \%, p=0.003)$. No parameter differed significantly between the pastinfected and uninfected groups (Table 2).
Table 1 The main clinical features in patients grouped by EBV detection

\begin{tabular}{|c|c|c|c|}
\hline Clinical features & $\begin{array}{l}\text { primary } \\
\text { infected } \\
(n=40)\end{array}$ & $\begin{array}{l}\text { past infected } \\
(n=48)\end{array}$ & $\begin{array}{l}\text { uninfected } \\
(n=76)\end{array}$ \\
\hline Age & 8-164 months & 2-163 months & 1-140 months \\
\hline 1-12 months & $3(7.50 \%)$ & $7(14.6 \%)$ & $20(26.3 \%)$ \\
\hline 12-36 months & $17(42.5 \%)$ & $11(22.9 \%)$ & $23(30.3 \%)$ \\
\hline 36-72 months & $8(20.0 \%)$ & $17(35.4 \%)$ & $21(27.6 \%)$ \\
\hline$>72$ months & $12(30.0 \%)$ & $13(27.1 \%)$ & $12(15.8 \%)$ \\
\hline Sex, male/female & $20 / 20$ & $20 / 18$ & $52 / 24$ \\
\hline Length of stay, days & $9.53 \pm 3.52^{*}$ & $7.71 \pm 3.07^{* *}$ & $9.11 \pm 4.11^{*}$ \\
\hline $\begin{array}{l}\text { Duration of fever, } \\
\text { days }\end{array}$ & $6.43 \pm 4.21$ & $6.04 \pm 4.19$ & $4.99 \pm 4.67$ \\
\hline Fever & $36(90 \%)$ & $42(87.5 \%)$ & $64(84.2 \%)$ \\
\hline Rash & $8(20.0 \%)$ & $9(18.8 \%)$ & $13(17.1 \%)$ \\
\hline Lymphadenopathy & $24(60.0 \%)^{*}$ & $14(29.2 \%)^{* *}$ & $29(38.2 \%)^{* *}$ \\
\hline Pharyngitis & $39(97.5 \%)$ & $45(93.8 \%)$ & $75(98.7 \%)$ \\
\hline Palatal petechiae & $9(22.5 \%)$ & $13(27.1 \%)$ & $16(21.1 \%)$ \\
\hline Hepatomegaly & $8(20.0 \%)^{*}$ & $9(18.8 \%)^{*}$ & $7(9.21 \%)^{* *}$ \\
\hline Splenomegaly & $4(10.0 \%)$ & $3(6.25 \%)$ & $4(5.26 \%)$ \\
\hline $\mathrm{ALC}<10 \%$ & $10 / 27(37.0 \%)^{*}$ & $11 / 26(42.3 \%)^{* *}$ & $11 / 46(23.9 \%)^{*}$ \\
\hline Elevated ESR & $16 / 28(57.1 \%)$ & 18/31 (58.1\%) & 19/43 (44.2\%) \\
\hline $\mathrm{CRP}>10 \mathrm{mg} / \mathrm{L}$ & $13 / 26(50.0 \%)^{*}$ & $22 / 33(66.7 \%)^{* *}$ & $31 / 48(64.6 \%)^{* *}$ \\
\hline ALF & $7 / 22(31.8 \%)$ & 5/18 (27.8\%) & 10/24 (41.7\%) \\
\hline WBC count, $10^{9} / \mathrm{L}$ & $11.94 \pm 8.58$ & $10.20 \pm 5.67$ & $10.47 \pm 5.99$ \\
\hline Neutrophils, \% & $40.48 \pm 24.43$ & $49.07 \pm 21.81$ & $41.99 \pm 26.24$ \\
\hline Lymphocytes, \% & $48.37 \pm 23.65$ & $39.86 \pm 22.03$ & $45.65 \pm 25.58$ \\
\hline Monocytes, \% & $9.98 \pm 6.12$ & $9.58 \pm 4.61$ & $9.86 \pm 6.26$ \\
\hline Platelets, $10^{9} / \mathrm{L}$ & $263.61 \pm 125.37$ & $\begin{array}{l}286.38 \pm \\
142.72\end{array}$ & $\begin{array}{l}288.90 \pm \\
130.82\end{array}$ \\
\hline Hemoglobin, g/L & $116.53 \pm 8.85$ & $117.68 \pm 10.83$ & $117.90 \pm 10.23$ \\
\hline
\end{tabular}

Between ${ }^{*}$ and ${ }^{*}$, the $p$ value $<0.05$. ALC: atypical lymphocytes; ESR: erythrocyte sedimentation rate; CRP: C-reactive protein; ALF: abnormal liver function (alanine aminotransferase or aspartate aminotransferase higher than 46 U/L); WBC: white blood cell.

\section{EBV or CMV infection and clinical features}

Patients were classified into three groups. Group A included 58 patients who had primary infection with EBV or CMV, group B consisted of 96 patients with past infection with EBV or CMV and group $C$ consisted of 36 patients uninfected with EBV or CMV. The clinical features of these groups are shown in Fig. 1. Compared with groups B and C, group A had longer hospital stays and lymphadenopathy, hepatomegaly, splenomegaly, atypical lymphocytes $>10 \%$ and abnormal liver function were more frequent. The proportion of patients with CRP $>10 \mathrm{mg} / \mathrm{L}$ was greater in group $C$ than in the other two groups $(p=0.03)$. There were no differences between groups A, B and C in duration of fever, incidence of fever, rash, pharyngitis and palatal petechiae or elevated erythrocyte sedimentation rate (ESR).

In addition, seven children showed both EBV and CMV primary infection (Table 3). Of these, six were less 
Table 2 The main clinical features in CMV-detected groups

\begin{tabular}{|c|c|c|c|}
\hline Clinical features & $\begin{array}{l}\text { primary infected } \\
(n=25)\end{array}$ & $\begin{array}{l}\text { past infected } \\
(\mathrm{n}=104)\end{array}$ & $\begin{array}{l}\text { uninfected } \\
(n=36)\end{array}$ \\
\hline Age & $1-110$ months & 2-164 months & 4-163 months \\
\hline 1-12 months & 7 (28.0\%) & $22(21.2 \%)$ & $12(30.6 \%)$ \\
\hline $12-36$ months & $8(32.0 \%)$ & $36(34.6 \%)$ & $11(36.1 \%)$ \\
\hline 36-72 months & $6(24.0 \%)$ & $25(24.0 \%)$ & $6(16.7 \%)$ \\
\hline$>72$ months & $4(16.0 \%)$ & $21(20.2 \%)$ & $6(16.7 \%)$ \\
\hline Sex, male/female & $17 / 8$ & $65 / 39$ & $24 / 12$ \\
\hline Length of stay, days & $13.04 \pm 4.16^{*}$ & $8.26 \pm 3.07^{* *}$ & $8.28 \pm 4.14^{* *}$ \\
\hline Duration of fever, days & $5.36 \pm 4.32$ & $4.96 \pm 4.38$ & $6.03 \pm 5.11$ \\
\hline Fever & 20 (80.0\%) & $82(78.8 \%)$ & 29 (80.6\%) \\
\hline Rash & $1(4.00 \%)^{*}$ & $24(23.1 \%)^{* *}$ & $7(19.4 \%)^{* *}$ \\
\hline Lymphadenopathy & $13(52.0 \%)$ & $37(35.6 \%)$ & $9(25 \%)$ \\
\hline Pharyngitis & $23(92.0 \%)$ & $101(97.1 \%)$ & $34(94.4 \%)$ \\
\hline Palatal petechiae & $10(40.0 \%)^{*}$ & $16(15.4 \%)^{* *}$ & $2(5.56 \%)^{* *}$ \\
\hline Hepatomegaly & $13(52.0 \%)^{*}$ & $12(11.5 \%)^{* *}$ & $2(5.56 \%)^{* *}$ \\
\hline Splenomegaly & $8(32.0 \%)^{*}$ & $3(2.88 \%)^{* *}$ & $1(2.78 \%)^{* *}$ \\
\hline $\mathrm{ALC}>10 \%$ & $12 / 16(75.0 \%)^{*}$ & $12 / 58(20.7 \%)^{* *}$ & $4 / 14(28.6 \%)^{* *}$ \\
\hline Elevated ESR & 8/14 (57.1\%) & $35 / 61$ (57.4\%) & 13/21 (61.9\%) \\
\hline $\mathrm{CRP}>10 \mathrm{mg} / \mathrm{L}$ & 8/15 (53.3\%) & $33 / 61$ (54.1\%) & 16/22 (72.7\%) \\
\hline ALF & $15 / 21(71.4 \%)^{*}$ & $9 / 37(24.3 \%)^{* *}$ & $3 / 13(23.1 \%)^{* *}$ \\
\hline WBC count, $10^{9} / \mathrm{L}$ & $14.42 \pm 8.31$ & $11.07 \pm 15.72$ & $9.07 \pm 6.14$ \\
\hline Neutrophils, \% & $24.15 \pm 15.70^{*}$ & $43.60 \pm 23.3^{* *}$ & $39.44 \pm 25.90^{* *}$ \\
\hline Lymphocytes, \% & $62.03 \pm 16.74^{*}$ & $44.79 \pm 22.39^{* *}$ & $48.92 \pm 25.57^{* *}$ \\
\hline Monocytes, \% & $10.63 \pm 5.81$ & $9.89 \pm 6.36$ & $9.63 \pm 4.90$ \\
\hline Platelets, $10^{9} / \mathrm{L}$ & $253.96 \pm 96.02$ & $304.72 \pm 143.25$ & $305.97 \pm 121.85$ \\
\hline Hemoglobin, g/L & $113.30 \pm 9.91$ & $118.59 \pm 11.92$ & $118.35 \pm 12.26$ \\
\hline
\end{tabular}

Between * and **, the $p$ value < 0.05 . ALC: atypical lymphocytes; ESR: erythrocyte sedimentation rate; CRP: C-reactive protein; ALF: abnormal liver function (alanine aminotransferase or aspartate aminotransferase higher than $46 \mathrm{U} / \mathrm{L}$ ); WBC: white blood cell.

than six years old. All seven patients showed the typical manifestations of IM-fever, pharyngitis and lymphadenopathy. Palatal petechiae, hepatomegaly and splenomegaly were each seen in four children (57.1\%) and none presented with rashes. The occurrence of liver function abnormalities was $80 \%(4 / 5)$ and an elevation in the proportion of atypical lymphocytes was observed in five children $(5 / 6,83.3 \%)$. White blood cell counts ranged from $7.88 \times 10^{9} / \mathrm{L}$ to $43.8 \times 10^{9} / \mathrm{L}$. Of the seven children, four had detectable specific IgM against one or more of the other 12 respiratory agents. The results showed one child positive for one type of IgM and the other three each positive for two types.

The disease spectrum in children with EBV/CMV infection The disease spectrum was diverse, especially the spectrum of EBV infection (Table 4). The most common disease caused by EBV primary infection was IM (21/40, $52.5 \%)$, followed by respiratory tract infection $(12 / 40$, $30.0 \%)$, Kawasaki disease $(1 / 40,2.5 \%)$, anaphylactic purpura $(1 / 40,2.5 \%)$, idiopathic thrombocytopenic purpura
$(1 / 40,2.5 \%)$, measles $(1 / 40,2.5 \%)$, asthma $(1 / 40,2.5 \%)$, juvenile rheumatoid arthritis $(1 / 40,2.5 \%)$ and ulcerative stomatitis $(1 / 40,2.5 \%)$. Of the diseases caused by CMV primary infection, the most common was also IM (14/ $25,56.0 \%)$, followed by respiratory tract infections $(9 / 25$, $36.0 \%)$.

\section{Coinfection of EBV/CMV with other pathogens}

Besides EBV and CMV, 162 patients had detectable specific IgM against the other 12 pathogens RSV, Adv, Flu $\mathrm{A}$ and B, PIV 1, 2, and 3, CP, MP, Haemophilus influenzae, Klebsiella pneumoniae and Legionella pneumophila. Of these patients, 60 (37.0\%) children were uninfected, a single agent was identified in 30 (18.5\%) children and two or more agents in $72(44.4 \%)$ children. Fig. 2 shows the details of coinfection with EBV or CMV and other pathogens. The general distribution of these 12 pathogens was similar in the patients with detectable antiEBV, anti-CMV and anti-EBV or anti-CMV. We detected coinfection of multiple other agents and EBV/ CMV in $68.9 \%$ of children, and in $63.6 \%$ of children 


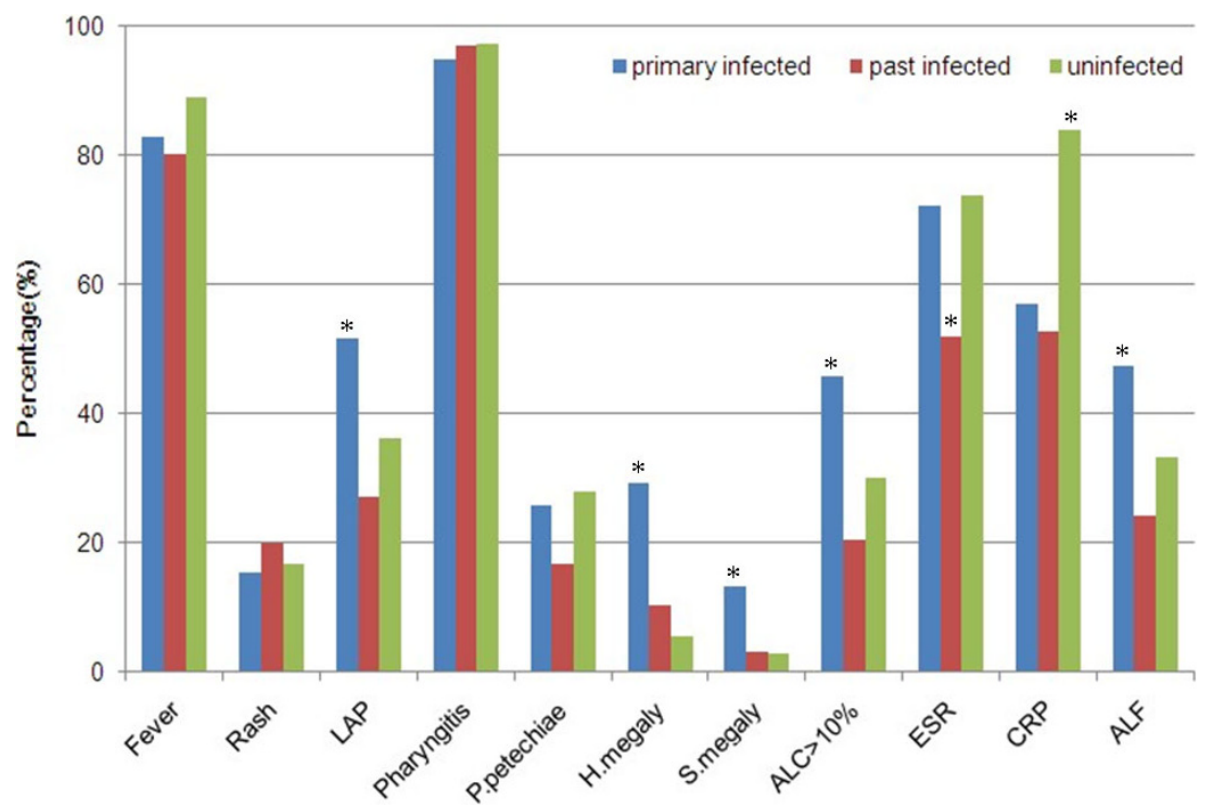

Figure 1 Main clinical features in patients grouped by detection of anti-EBV or anti-CMV antibodies. *Differs from the other two groups, $p<$ 0.05. LAP: Iymphadenopathy; P. petechiae: palatal petechiae; H.megaly: hepatomegaly; S.megaly: splenomegaly; ALC: atypical lymphocytes; ESR: erythrocyte sedimentation rate; CRP: C-reactive protein; ALF: abnormal liver function (alanine aminotransferase or aspartate aminotransferase higher than $46 \mathrm{U} / \mathrm{L})$.

with only anti-EBV or anti-EBV or anti-CMV. In the group with only anti-CMV antibodies detected, the proportion was higher at $81.3 \%$, which differed significantly from the past-infected and uninfected groups.

Table 3 Clinical features of the seven children with EBV and CMV primary infection

\begin{tabular}{|c|c|c|c|c|c|c|c|}
\hline \multirow[t]{2}{*}{ Clinical features } & \multicolumn{7}{|c|}{ Patients } \\
\hline & $\mathrm{N}^{\circ} 1$ & $\mathrm{~N}^{\circ} 2$ & $N^{\circ} 3$ & $N^{\circ} 4$ & $\mathrm{~N}^{\circ} 5$ & $N^{\circ} 6$ & $N^{\circ} 7$ \\
\hline Age, months & 73 & 59 & 16 & 24 & 65 & 13 & 24 \\
\hline Sex & female & male & female & male & male & male & male \\
\hline Fever & + & + & + & + & + & + & + \\
\hline Lymphadenopathy & + & + & + & + & + & + & + \\
\hline Pharyngitis & + & + & + & + & + & + & + \\
\hline Palatal petechiae & - & + & + & + & + & - & - \\
\hline Rash & - & - & - & - & - & - & - \\
\hline Hepatomegaly & - & + & + & - & + & - & + \\
\hline Splenomegaly & - & + & + & + & + & - & - \\
\hline $\mathrm{ALT}, \mathrm{U} / \mathrm{L}$ & / & 18 & 77 & 70 & 256 & 77 & / \\
\hline AST, U/L & / & 28 & 84 & 56 & 54 & 78 & / \\
\hline WBC count, $10^{9} / \mathrm{L}$ & 7.88 & 16.2 & 27.6 & 22.0 & 9.14 & 43.8 & 10.5 \\
\hline Lymphocyte, \% & 29.3 & 70.7 & 77.4 & 47.7 & 75.3 & 87.0 & 43.3 \\
\hline $\mathrm{ALC}, \%$ & 4 & / & 58 & 57 & 37 & 15 & 56 \\
\hline $\begin{array}{l}\text { Other positive } \\
\text { agents }\end{array}$ & $\begin{array}{l}C P \\
M P\end{array}$ & / & MP & / & / & $\begin{array}{l}\text { Adv, } \\
K P\end{array}$ & $\begin{array}{l}\text { Adv, } \\
\text { MP }\end{array}$ \\
\hline
\end{tabular}

ALC: atypical lymphocytes; ALT: alanine aminotransferase; AST: aspartate aminotransferase; WBC: white blood cell; CP: Chlamydia pneumoniae; MP: Mycoplasma pneumoniae; KP: Klebsiella pneumoniae; Adv: adenovirus.
The patients were divided into six groups based on the results of testing for antibodies to EBV or CMV and the other 12 pathogens (Table 5). We compared the clinical manifestations of these six groups. The symptoms and physical signs seemed to be most severe in the patients of group A (i.e., the patients with EBV or CMV primary infection and two or more other pathogens). In this group, fever, rash, lymphadenopathy, hepatomegaly, splenomegaly, atypical lymphocytes $>10 \%$ and abnormal liver function were all very frequent. In addition, the length of hospital stay and the duration of fever were longer than in groups $\mathrm{C}, \mathrm{D}$ and $\mathrm{F}$.

Fig. 3 shows that in the primary-infection group, coinfection with two or three pathogens was most frequent, with the percentage first increasing then decreasing when the number of pathogens was more than two. In this group, up to seven pathogens were detected in individual patients. The incidence of coinfection decreased with the number of pathogens in past-infected and uninfected children. In the primary-infection group, the most frequent combination was coinfection of EBV/ CMV with two other agents, while one episode involved coinfection with five agents and one episode involved coinfection with seven agents.

The distribution of the 12 pathogens in the multiply infected patients is presented in Table 6. Overall, the most frequent pathogens in the EBV/CMV primary infection group were Flu A and Flu B, followed by CP. In the 
Table 4 The disease spectrum in EBV or CMV primary infected children

\begin{tabular}{lllll}
\hline Diagnosis & \multicolumn{2}{l}{ EBV primary infected $(\mathbf{n}=\mathbf{4 0})$} & \multicolumn{2}{l}{ CMV primary infected $(\mathbf{n}=\mathbf{2 5})$} \\
\cline { 2 - 5 } & $\mathbf{N}$ & Percentage (\%) & $\mathbf{N}$ & Percentage (\%) \\
\hline IM & 21 & 52.5 & 14 & 56.0 \\
Respiratory infection & 12 & 30.0 & 9 & 36.0 \\
Kawasaki disease & 1 & 2.5 & & \\
Anaphylactic purpura & 1 & 2.5 & & \\
Measles & 1 & 2.5 & & \\
Ulcerative stomatitis & 1 & 2.5 & & 4.0 \\
Asthma & 1 & 2.5 & 1 & 4.0 \\
JRA & 1 & 2.5 & 1 & \\
ITP & 1 & 2.5 & & \\
Hyperbilirubinemia & & & & \\
Infantile hepatitis & & & & \\
\hline
\end{tabular}

IM: infectious mononucleosis; ITP: idiopathic thrombocytopenic purpura; JRA: juvenile rheumatoid arthritis.

past-infected group, K. pneumoniae was most frequent, and MP was most frequent in EBV/CMV-uninfected children. The incidence of RSV, ADV, MP, Flu A, PIV 1 and PIV 2 did not differ between EBV/CMV-uninfected children and those with primary or past infection. The incidence of CP in the primary-infection group was significantly higher than in the other groups $(p<0.001)$. There was a significantly higher proportion of Flu B $(p=0.003)$ in uninfected children than in the other groups. In the primary-infection and uninfected groups, the proportion infected with PIV 3 was the same and was significantly higher than in children with past EBV/CMV infection $(p=0.014)$. H. influenzae was more frequent in the past-infected group compared with the primaryinfection group, but did not differ compared with the uninfected group. The incidence of K. pneumoniae in past-infected children was significantly higher than that in uninfected patients or those with primary infection $(p<0.001)$.

\section{Discussion}

EBV and CMV, members of the herpesvirus family, establish lifelong latent infection. More than $90 \%$ of adults have acquired these two viruses [2]. Infants from families of lower socioeconomic levels tend to become infected somewhat earlier than those from better-situated families. In developed countries, primary EBV infection can often be delayed to occur in adolescents and young adults, while in developing countries the prevalence of IgG antibodies to VCA of EBV can be up to $80 \%$ by the

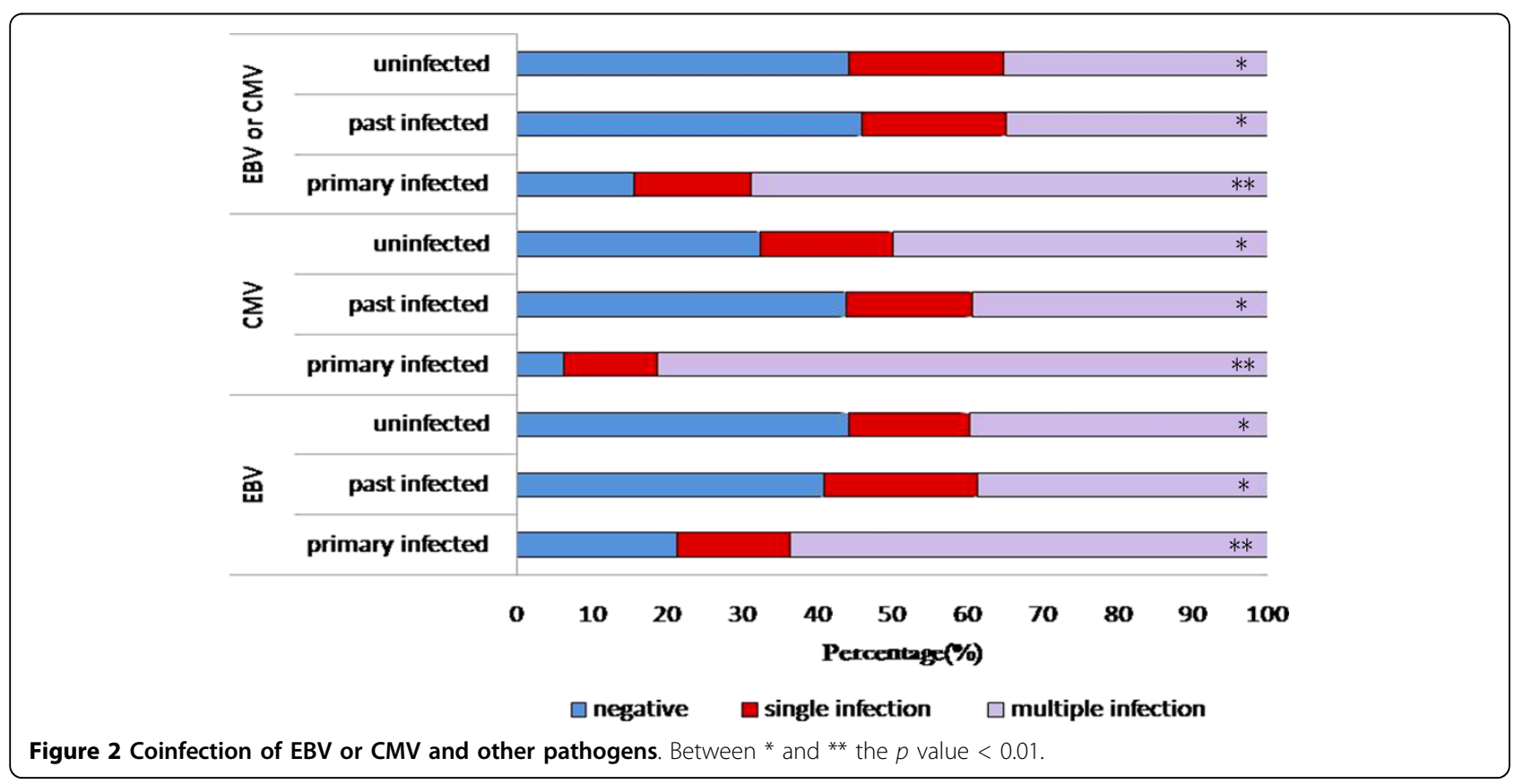


Table 5 The differences in the main clinical features of children with multiple infections or a single infection

\begin{tabular}{lllllll}
\hline Clinical features & $\mathbf{A}(\mathbf{n}=\mathbf{3 1})$ & $\mathbf{B}(\mathbf{n}=\mathbf{1 4})$ & $\mathbf{C}(\mathbf{n}=\mathbf{2 9})$ & $\mathbf{D}(\mathbf{n}=\mathbf{5 4})$ & $\mathbf{E}(\mathbf{n}=\mathbf{1 2})$ & $\mathbf{F}(\mathbf{n}=\mathbf{2 2})$ \\
\hline H. stay, days & $10.87 \pm 4.11^{* *}$ & $10.07 \pm 4.23$ & $7.69 \pm 3.24^{*}$ & $8.09 \pm 3.15^{*}$ & $9.08 \pm 3.23$ & $7.73 \pm 3.88^{*}$ \\
D. of fever, days & $7.39 \pm 3.93^{* *}$ & $5.79 \pm 4.89$ & $4.62 \pm 4.07^{*}$ & $4.80 \pm 4.44^{*}$ & $7.33 \pm 5.63$ & $4.32 \pm 3.20^{*}$ \\
Fever & $30(96.8 \%)^{* *}$ & $11(78.6 \%)^{*}$ & $22(75.9 \%)^{*}$ & $43(79.6 \%)^{*}$ & $11(78.6 \%)^{*}$ & $19(86.4 \%)^{*}$ \\
Rash & $7(22.6 \%)$ & $0(0)$ & $7(24.1 \%)$ & $9(16.7 \%)$ & $1(8.33 \%)$ & $5(22.7 \%)$ \\
Lymphadenopathy & $16(51.6 \%)^{* *}$ & $7(50.0 \%)^{* *}$ & $9(31.0 \%)^{*}$ & $13(24.1 \%)^{*}$ & $3(25.0 \%)^{*}$ & $9(40.9 \%)$ \\
Pharyngitis & $31(100 \%)$ & $13(92.9 \%)$ & $28(96.6 \%)$ & $52(96.3 \%)$ & $11(91.7 \%)$ & $22(100 \%)$ \\
Palatal petechiae & $6(19.4 \%)$ & $4(28.6 \%)$ & $6(20.7 \%)$ & $8(14.8 \%)$ & $4(33.3 \%)$ & $4(18.2 \%)$ \\
Hepatomegaly & $7(22.6 \%)^{*}$ & $3(21.4 \%)^{*}$ & $3(10.3 \%)^{* *}$ & $4(7.41 \%)^{* *}$ & $0(0)$ & $2(9.09 \%)^{* *}$ \\
Splenomegaly & $3(9.38 \%)$ & $1(7.41 \%)$ & $1(3.45 \%)$ & $2(3.70 \%)$ & $0(0)$ & $1(4.55 \%)$ \\
ALC > 10\% & $8 / 10(80.0 \%)^{* *}$ & $5 / 10(50.0 \%)^{* *}$ & $2 / 10(20.0 \%)^{*}$ & $8 / 32(25.0 \%)^{*}$ & $2 / 7(28.6 \%)^{*}$ & $4 / 12(33.3 \%)^{*}$ \\
Elevated ESR & $14 / 17(82.4 \%)^{* *}$ & $7 / 9(77.8 \%)^{*}$ & $11 / 18(61.1 \%)^{*}$ & $15 / 29(51.7 \%)^{*}$ & $5 / 5(100 \%)^{* *}$ & $8 / 13(61.5 \%)^{*}$ \\
CRP > 10 mg/L & $9 / 17(52.9 \%)^{*}$ & $5 / 10(50.0 \%)^{*}$ & $9 / 18(50.0 \%)^{*}$ & $16 / 32(50.0 \%)^{*}$ & $7 / 7(100 \%)^{* *}$ & $12 / 15(80.0 \%)^{* *}$ \\
ALF & $9 / 18(50.0 \%)^{*}$ & $3 / 7(42.3 \%)^{*}$ & $0 / 7(0)$ & $4 / 17(23.5 \%)^{* *}$ & $0 / 3(0)$ & $2 / 3(66.7 \%)^{*}$
\end{tabular}

A. EBV/CMV primary infection with multiple pathogens. B. EBV/CMV primary infection with a single or no other pathogen. C. EBV/CMV past infection with multiple pathogens. D. EBV/CMV past infection with a single or no other pathogen. E. EBV/CMV-uninfected children with multiple pathogens. F. EBV/CMVuninfected children with a single or no other pathogen. Between * and **, the $p$ value $<0.05$. H. stay: hospital stay; D. of fever: duration of fever; ALC: atypical lymphocytes; ESR: erythrocyte sedimentation rate; CRP: C-reactive protein; ALF: abnormal liver function (alanine aminotransferase or aspartate aminotransferase higher than $46 \mathrm{U} / \mathrm{L})$; WBC: white blood cell.

age of five years without detectable symptoms being reported[15]. In this study there were only 63 children (38.4\%) under six years old with EBV primary or past infection. The reason why this percentage is much lower than that in previous studies may be that the objects selected for this study presented with some symptoms of IM. Some authors have noted that maternal antibodies to
EBV, most of which disappear by four months of age, may serve to prevent the infection during early infancy [2]. EBV primary infection can occur in infants 2-3 months after the disappearance of maternal antibody [16], meaning that EBV primary infection may occur in infants at six months of age. A study in 2001 in Hong Kong found that the earliest appearance of EBV primary

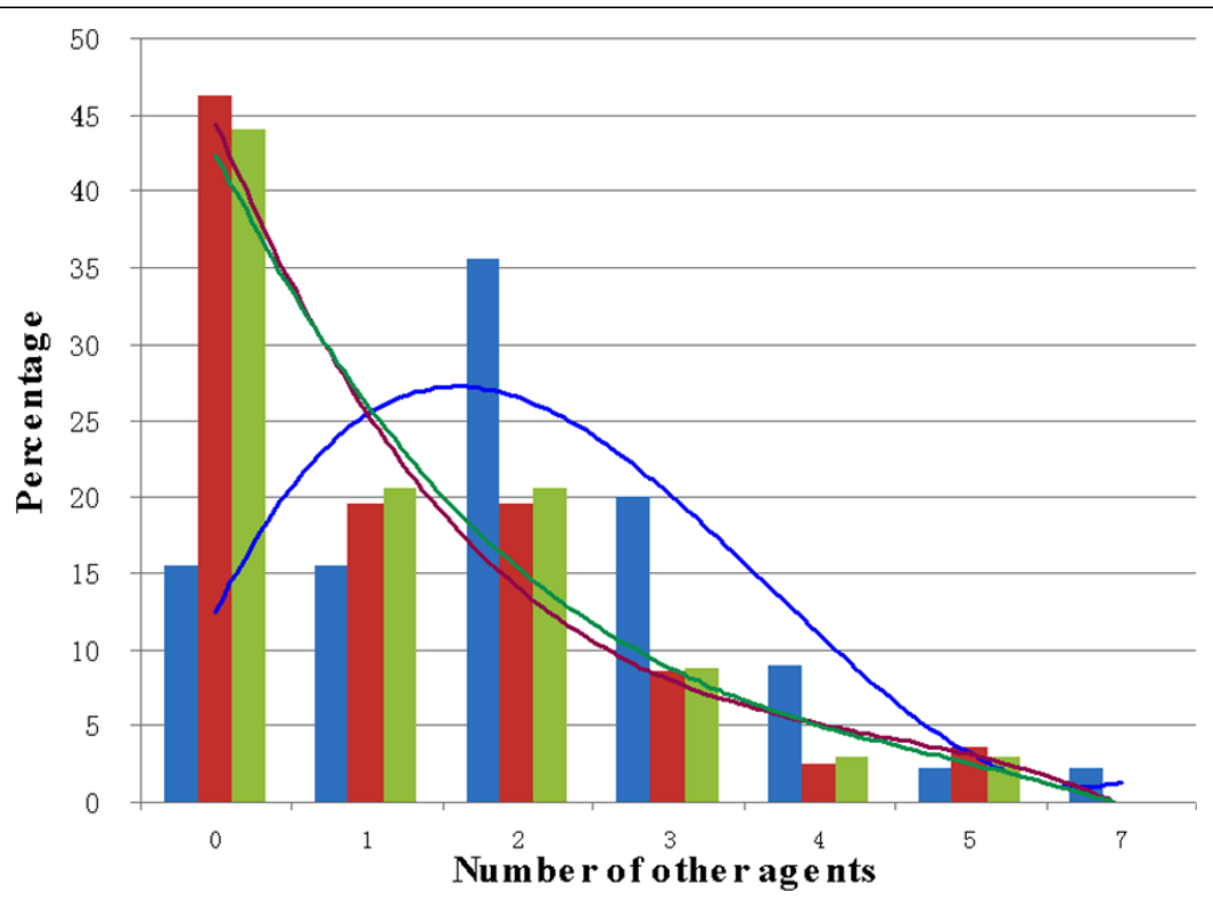

primary infected ast infected uninfected

Figure 3 Correlations between the percentage of patients and the number of pathogens in children with multiple infections. 
Table 6 The distribution of the other 12 pathogens in multiply infected children

\begin{tabular}{llll}
\hline & primary infected & past infected & uninfected \\
\hline RSV & $9 / 31(29.0)$ & $6 / 28(21.4)$ & $2 / 12(16.7)$ \\
ADV & $11 / 31(35.5)$ & $11 / 28(39.3)$ & $3 / 12(25.0)$ \\
CP & $16 / 31(51.6)^{* *}$ & $7 / 28(25.0)^{*}$ & $3 / 12(25.0)^{*}$ \\
MP & $15 / 31(48.4)$ & $12 / 28(42.9)$ & $4 / 12(33.3)$ \\
Flu A & $12 / 20(60.0)$ & $13 / 18(72.2)$ & $6 / 10(60.0)$ \\
Flu B & $12 / 20(60.0)^{*}$ & $11 / 18(61.1)^{*}$ & $8 / 10(80.0)^{* *}$ \\
PIV 1 & $2 / 20(10.0)$ & $2 / 18(7.14)$ & $0 / 10(0)$ \\
PIV 2 & $1 / 20(5.00)$ & $1 / 18(3.57)$ & $0 / 10(0)$ \\
PIV 3 & $4 / 20(20.0)^{*}$ & $2 / 18(7.14)^{* *}$ & $2 / 10(20.0)^{*}$ \\
H. influenzae & $1 / 20(5.00)^{*}$ & $3 / 18(16.7)^{* *}$ & $1 / 10(10.0)$ \\
K. pneumoniae & $4 / 20(20.0)^{*}$ & $8 / 18(44.4)^{* *}$ & $2 / 10(20.0)^{*}$ \\
L. pneumophila & $0 / 20(0)$ & $0 / 18(0)$ & $1 / 10(10.0)$ \\
\hline
\end{tabular}

Between * and **, the $p$ value $<0.05$. RSV: respiratory syncytial virus; Adv: adenovirus; Flu: influenza virus; PIV: parainfluenza virus; CP: Chlamydia pneumoniae; MP: Mycoplasma pneumoniae; $H$. influenzae: Haemophilus influenzae; K. pneumoniae: Klebsiella pneumoniae; L. pneumophila: Legionella pneumophila.

infection occurred in some babies at eight months of age [2], while in our study the youngest infant with EBV past infection (positive for both VCA-IgG and EBNA-IgG) was only two months of age. This should rule out the possibility of protection from maternal antibodies to EBV-VCA and EBNA.

The defensive responses to infection with EBV/CMV can be limited or very broad, which leads to diverse clinical manifestations of infection. The majority of patients with primary infections are usually asymptomatic, except for the acute infectious mononucleosis that is most common in China in children in the 3-6 years age group [15]. Our results showed that the only significant differences in patients with EBV primary infection compared with those having past infection or no infection were a higher incidence of lymphadenopathy and longer hospital stays. The patients in the CMV primary-infection group had longer hospital stays and higher frequency of palatal petechiae, hepatomegaly, splenomegaly, atypical lymphocytes $>10 \%$ and abnormal liver function, but fewer rashes than the other two groups. This suggested that the differences in clinical features among the CMV-infected groups occurred much earlier than those among the EBV-infected groups. In addition, in this study seven children showed both EBV and CMV primary infection. They all presented with the typical manifestations of IM and with a high occurrence of hepatomegaly (57.1\%), splenomegaly $(57.1 \%)$ and liver function abnormalities $(80.0 \%)$. The rate of coinfection with other pathogens was as high as $100 \%(5 / 5)$, and the prevalence of multi-pathogen infection was up to $80 \%(4 / 5)$, which was higher than that of the children with a single EBV or CMV infection. Some authors have reported cases of children with both EBV and CMV infection and noted that the course of disease in these children was longer, but the last word is not yet in on whether coinfection with both EBV and CMV can cause other more serious clinical manifestations $[8,9]$.

The disease spectrum of EBV/CMV primary infection is very diverse, with the most common manifestation being IM. In most studies published outside China, about $50 \%$ of children with EBV infection develop IM [17], and the proportion of IM seen in our study was similar (52.5\%), which is much higher than other studies in China. In most Chinese studies, the proportion of IM in the disease spectrum is only about $20 \%$, and the most common effect is respiratory tract infection (about $40 \%$ compared with $30 \%$ in our study)[15]. The disease spectrum of EBV infection is more diverse than that of CMV infection. In addition to IM and respiratory tract infection, Kawasaki disease, anaphylactic purpura, idiopathic thrombocytopenic purpura, measles, asthma, juvenile rheumatoid arthritis and other complications have been reported. Other diseases have also been reported including viral encephalitis, facial paralysis, myocarditis, lymphoma, hemophagocytic syndrome and systemic lupus erythematosus[15]. The complexity of the manifestations and the variety of the disease spectrum of EBV/CMV primary infection suggest that our pediatricians should make the diagnosis based on a comprehensive analysis.

The notable finding in our study was the presence of coinfection of multiple other agents with EBV/CMV in more than $60 \%$ of the children. In the groups with detectable CMV antibodies without EBV, this proportion was as high as $81.3 \%$. The most frequent combination was coinfection with two agents. Research on multiple infections accompanying EBV/CMV infection is relatively rare. The prevalence of mixed infection in previous studies is lower than $10 \%$ in young children with IM, with the most frequent combination being coinfection with two other pathogens [12]. In contrast, we found a much higher incidence of coinfection with more than two agents.

The differences in the incidence of coinfection may be due to the different types of etiological agents involved or to the different diagnostic methods applied $[18,19]$. All of the 12 respiratory pathogens detected in our study are active in cold and dry environments. It is possible that these agents would be associated with EBV/ CMV because they circulate most frequently at the same time of year [20]. The use of the IIF method to detect antibodies to respiratory pathogens may be another cause of the higher rate of coinfection in our study. IIF is only a qualitative method to detect antibodies, and the existence of IgM antibodies cannot guarantee that the child was infected with multiple pathogens 
at the same time. In most studies, IgM antibodies can be detected in more than $70 \%$ of children with an acute respiratory tract infection within one week of onset of infection, after which the IgM level gradually declines and becomes undetectable three months after the onset of infection. Thus, the IIF method to detect antibodies may merely indicate that a child has been infected with a respiratory pathogen between one week and three months before the sample was obtained [14].

In the patients with multipathogen infections, EBV/ CMV may be a primary, co-primary, or secondary pathogen. It may be reactivated in the course of infection with another agent or, possibly, it may precipitate infection with some other organism by suppressing immune function. We prefer the latter hypothesis. Transient immunosuppression secondary to EBV/CMV infection has been well described. During the early phase of acute EBV-related IM, dramatic antigen-driven clonal expansions of CD8 $\mathrm{T}$ lymphocytes with an abnormally low $\mathrm{CD} 4+/ \mathrm{CD} 8+$ ratio were detected [21-23]. Furthermore, B-cell function was impaired and the production of antibody against other pathogens was inhibited $[24,25]$, but these abnormalities disappeared during the convalescent phase. This demonstrates that infection with EBV can affect both cell-mediated and humoral immunity, and causes a broad-based transient immunosuppression. This immunosuppression may be severe enough to cause secondary infections in some EBVinfected individuals, as illustrated by the report of severe measles and severe RSV pneumonia in patients infected with EBV $[10,13,26]$. However, whether it is the EBV/ $C M V$ infection that causes a mixed infection, or whether the EBV/CMV infection coexists with these diseases is worthy of further exploration.

In this study, the symptoms and physical signs seemed to be most severe in the patients with EBV/CMV primary infection and multiple pathogens. Although there are no similar reports, patients coinfected with EBV/ CMV and a single other pathogen such as CP or RSV were reported to suffer more severe symptoms $[10,11]$. In the multiply infected patients, the distribution of the 12 additional pathogens is not random (Table 6). Coinfection with certain pathogens occurs more frequently than expected in the patients with EBV/CMV primary infection: CP and PIV 3 were more frequently seen and in contrast, all three bacteria were rarer. There have been no previous reports of similar findings.

In conclusion, we found frequent multipathogen infections in children admitted with EBV/CMV infection, and the distribution of these pathogens was not random. Despite this, because most of the children with coinfection of EBV/CMV and multiple pathogens are severely affected, the diagnosis is very important to make.
Further studies are needed to clarify the pathogenesis and interactions involved in coinfection by different pathogens.

\section{Study Design \\ Case selection}

One hundred and ninety patients, including 120 boys and 70 girls with ages ranging from 1-164 months (mean $43.5 \pm 35.4$ months), were enrolled for the retrospective study. All were admitted to Zhongnan Hospital of Wuhan University, China, between August 2008 and September 2009 with suspected IM because they presented with either (1) at least three of the EBV-related symptoms of fever, rash, lymphadenopathy, pharyngitis, palatal petechiae, hepatomegaly, or splenomegaly, or (2) fever of duration longer than seven days. In addition, all EBV-associated malignant diseases such as malignant lymphoma and chronic active EBV infection were excluded.

\section{Case definition}

$E B V$-infected patients Primary infection: presence of IgM to viral capsid antigen (VCA) is conventionally used for diagnosing acute EBV infection. However, VCA-IgM is usually transient and quickly disappears, and the test may not be sufficiently sensitive [27-30]. Therefore, in our study, we used an alternative approach to define primary EBV infection as detection of either positive IgG to the early antigen (EA) or low-affinity anti-VCA-IgG or both.

Past infection: positive for IgG to VCA and IgG to Epstein-Barr nuclear antigen (EBNA), or detection of high-affinity anti-VCA-IgG without VCA-IgM and EA-IgG.

Uninfected: no antibodies to EBV detected.

$C M V$-infected patients Primary infection: positive for CMV-IgM.

Past infection: detection of CMV-IgG without CMV-IgM.

Uninfected: no antibodies to CMV detected [31].

\section{Procedures}

In this study, a peripheral blood sample was obtained from all children within the first $24 \mathrm{~h}$ of admission to the pediatric department. Specific antibodies to EBV and CMV (IgM and IgG to VCA, IgG to EA and EBNA of EBV, IgM and IgG to CMV) were detected by indirect immunofluorescence (IIF). Ninety-three children had an additional test for the affinity of IgG against VCA of EBV (EUROIMMUN, Lübeck, Germany). Moreover, specific antibodies (IgM, IgG) to another 12 respiratory pathogens (respiratory syncytial virus (RSV), adenovirus (Adv), influenza virus (Flu) types A and B, parainfluenza virus (PIV) types 1, 2, and 3, Chlamydia pneumoniae (CP) and Mycoplasma pneumoniae (MP), Haemophilus 
influenzae, Klebsiella pneumoniae and Legionella pneumophila) were detected using a commercial indirect immunofluorescence (IIF) kit (EUROIMMUN, Lübeck, Germany) following the manufacturer's instructions.

For each patient, the medical history, age of onset, forewarning signs, symptoms, complications and laboratory data at diagnosis were collected and analyzed.

\section{Statistical analysis}

General data are presented as the percentage or mean \pm standard deviation (SD). All statistical analyses were performed using SPSS software (version 13; Chicago, IL, USA). The chi-square test was used to compare between-group differences in percentages. The differences among the mean values of white blood cell counts, hemoglobin and platelets were analyzed using a one-way ANOVA. $p<0.05$ was considered significant.

\section{Abbreviations}

EBV: Epstein-Barr virus; CMV: Cytomegalovirus; RSV: respiratory syncytial virus; Adv: adenovirus; Flu: influenza virus; PIV: parainfluenza virus; CP: chlamydia pneumoniae; MP: mycoplasma pneumoniae; IM: infectious mononucleosis; VCA: viral capsid antigen; EA: early antigen; EBNA: Epstein-Barr nuclear antigen; IIF: indirect immunofluorescence

\section{Acknowledgements}

This work was supported by China National Natural Science Foundation (No. 30973220).

\section{Author details}

${ }^{1}$ Pediatrics Department, Zhongnan Hospital, Wuhan University, Wuhan 430071, China. ${ }^{2}$ The Sixth People's Hospital of Hangzhou, Hangzhou Children's Hospital, Hangzhou, China.

\section{Authors' contributions}

$\mathrm{XW}$ wrote the manuscript and collected the data; KY, CW, YH discussed and reviewed the manuscript. DZ designed the manuscript and analyzed the data; all authors read and approved the final manuscript.

\section{Competing interests}

The authors declare that they have no competing interests.

Received: 4 June 2010 Accepted: 21 September 2010 Published: 21 September 2010

\section{References}

1. Mocarski ES, Shenk T, Pass RF: Cytomegaloviruses. In Fields Virology. Edited by: Knipe DM, Howley PM. Lippincott Williams , 5 2007:2701-72.

2. Cohen J: Epstein-Barr virus infection. N Engl J Med 2000, 343:481-492.

3. Chan KH, Tam JS, Peiris JS, Seto WH, Ng MH: Epstein-Barr virus (EBV) infection in infancy. J Clin Virol 2001, 21:57-62.

4. Taylor GH: Cytomegalovirus. Am Fam Physician 2003, 67:519-524.

5. Kim JE, Oh SH, Kim KM, Chio BH, Kim DY, Cho HR, Lee YJ, Rhee KW, Park SJ, Lee YJ, Lee SG: Infections after living donor liver transplantation in children. J Korean Med Sci 2010, 25:527-531.

6. Owayed AF, Campbell DM, Wang EEL: Underlying causes of recurrent pneumonia in children. Arch Pediatr Adolesc Med 2000, 154:190-194.

7. Álvarez-Lafuente R, Aguilera B, Suárez-Mier MP, Morentin B, Vallejo G, Gómez J, Fernández-Rodríguez A: Detection of human herpesvirus-6, Epstein-Barr virus and cytomegalovirus in formalin-fixed tissues from sudden infant death: a study with quantitative real-time PCR. Forensic Sci Int 2008, 178:106-111.
8. Ito Y, Shibata-Watanabe Y, Kawada J, Maruyama K, Yagasaki H, Kojima S, Kimura $\mathrm{H}$ : Cytomegalovirus and Epstein-Barr virus coinfection in three toddlers with prolonged illnesses. J Med Virol 2009, 81:1399-1402.

9. Zenda T, Itoh Y, Takayama Y, Masunaga T, Asaka S, Oiwake H, Shinozaki K, Takeda R: Significant liver injury with dual positive IgM antibody to Epstein-Barr virus and cytomegalovirus as a puzzling initial manifestation of infectious mononucleosis. Intern Med 2004, 43:340-343.

10. Abughali N, Khiyami A, Birnkrant DJ, Kumar ML: Severe respiratory syncytial virus pneumonia associated with primary Epstein-Barr virus infection. Pediatr Pulmonol 2002, 33:395-398.

11. Van der Laan NE, Voerman BJ, Rustemeijer C, van der Hoeven KJ: Peritonitis, moderate ascites and hepatitis due to infection with Chlamydia trachomatis and Epstein-Barr virus in a young woman. Diagnosis by polymerase chain reaction from peritoneal tissue. Neth $J$ Med 1995, 46:41-43.

12. Mehraein Y, Lennerz C, Ehlhardt S, Zang KD, Madry H: Replicative multivirus infection with cytomegalovirus, herpes simplex virus 1 and parvovirus B19 and latent Epstein-Barr virus infection in the synovial tissue of a psoriatic arthritis patient. J Clin Virol 2004, 31:25-31.

13. Atrasheuskaya AV, Kameneva SN, Neverov AA, Ignatyev GM: Acute infectious mononucleosis and coincidental measles virus infection. J Clin Virol 2004, 31:160-164.

14. Peng D, Zhao D, Liu J, Wang X, Yang K, Hong X: Multipathogen infections in hospitalized children with acute respiratory infections. Virol J 2009, 6:155

15. Chan CW, Chiang AK, Chan RH, Lau AS: Epstein-Barr virus-associated infectious mononucleosis in Chinese children. Pediatr Infect Dis J 2003, 22:974-978.

16. Biggar RJ, Henle W, Fleisher G, Böcker J, Lennette ET, Henle G: Primary Epstein-Barr virus infections in African infants. Decline of maternal antibodies and time of infection. Int J Cancer 1978, 22:239-243.

17. Macsween KF, Crowford DH: Epstein Barr Virus recent advances. Lancet Infect Dis 2003, 3:131-140.

18. Choi EH, Lee HJ, Kim SJ, Eun BW, Kim NH, Lee JA, Lee JH, Song EK, Kim SH, Park JY, Sung JY: The association of newly identified respiratory viruses with lower respiratory tract infections in Korean children, 2000-2005. Clin Infect Dis 2006, 43:585-592.

19. Kuypers J, Wright N, Ferrenberg J, Huang ML, Cent A, Corey L, Morrow R: Comparison of real-time PCR assays with fluorescent antibody assays for diagnosis of respiratory virus infections in children. J Clin Microbio/ 2006, 44:2382-2388.

20. Cilla G, Oñate E, Perez-Yarza EG, Montes M, Vicente D, Perez-Trallero E: Viruses in community-acquired pneumonia in children aged less than 3 years old: High rate of viral coinfection. J Med Virol 2008, 80:1843-1849.

21. Ohga S, Nomura A, Takada H, Hara T: Immunological aspects of EpsteinBarr virus infection. Crit Rev Oncol Hematol 2002, 44:203-215.

22. Scherrenburg J, Piriou ER, Nanlohy NM, van Baarle D: Detailed analysis of Epstein-Barr virus-specific CD4+ and CD8+ T cell responses during infectious mononucleosis. Clin Exp Immunol 2008, 153:231-239.

23. Wingate PJ, McAulay KA, Anthony IC, Crawford DH: Regulatory T Cell Activity in Primary and Persistent Epstein-Barr Virus Infection. J Med Virol 2009, 81:870-877.

24. Junker AK, Ochs HD, Clark EA, Puterman ML, Wedgwood RJ: Transient immune deficiency in patients with acute Epstein-Barr virus infection Clin Immunol Immunopathol 1986, 40:436-446.

25. Dorner M, Zucol F, Berger C, Byland R, Melroe GT, Bernasconi M, Speck RF, David Nadal: Distinct ex vivo susceptibility of B-cell subsets to EpsteinBarr virus infection according to differentiation status and tissue origin. J Virol 2008, 82:4400-4412.

26. Gärtner B, Preiksaitis JK: EBV viral load detection in clinical virology. J Clin Virol 2010, 48:82-90.

27. Tamaro G, Donato M, Princi T, Parco S: Correlation between the immunological condition and the results of immunoenzymatic tests in diagnosing infectious mononucleosis. Acta BioMed 2009, 80:47-50.

28. Binnicker MJ, Jespersen DJ, Harring JA, Rollins LO, Beito EM: Evaluation of a multiplex flow immunoassay for detection of Epstein-Barr Virus-specific antibodies. Clin Vaccine Immunol 2008, 15:1410-1413. 
29. Robertson P, Beynon S, Whybin R, Brennan C, Vollmer-Conna U, Hickie I, Lloyd A: Measurement of EBV-IgG anti-VCA avidity aids the early and reliable diagnosis of primary EBV infection. J Med Virol 2003, 70:617-623.

30. Chan KH, Luo RX, Chen HL, NG MH, Seto WH, Peiris JSM: Development and evaluation of an Epstein-Barr Virus (EBV) immunoglobulin M enzyme-linked immunosorbent assay based on the 18-KDa matrix protein for diagnosis of primary EBV infection. J Clin Microbiol 1998, 36:3359-3361.

31. Just-Nübling G, Korn S, Ludwig B, Stephan C, Doerr HW, Preiser W: Primary cytomegalovirus infection in an outpatient setting-laboratory markers and clinical aspects. , Infection 2003,31:318-323.

doi:10.1186/1743-422X-7-247

Cite this article as: Wang et al: Coinfection with EBV/CMV and other respiratory agents in children with suspected infectious mononucleosis. Virology Journal 2010 7:247.

\section{Submit your next manuscript to BioMed Central} and take full advantage of:

- Convenient online submission

- Thorough peer review

- No space constraints or color figure charges

- Immediate publication on acceptance

- Inclusion in PubMed, CAS, Scopus and Google Scholar

- Research which is freely available for redistribution

Submit your manuscript at www.biomedcentral.com/submit 